Check for updates

Cite this: RSC Adv., 2018, 8, 42133

Received 30th September 2018

Accepted 19th November 2018

DOI: $10.1039 / c 8 r a 08109 c$

rsc.li/rsc-advances

\section{Tribological properties of nano-graphite as an additive in mixed oil-based titanium complex grease}

\begin{abstract}
Ming Niu (D) and Jianjun Qu*
Nano-graphite was chosen as an additive to improve the tribological properties of titanium complex grease. The influence of the concentration of nano-graphite ( $\mathrm{N}-\mathrm{G}$ ) with three average diameter sizes ( $2 \mu \mathrm{m}, 3.5 \mu \mathrm{m}$, and $6 \mu \mathrm{m}$ ) on the tribological properties of titanium complex grease was researched. It was determined that the optimum concentration of the three types of $\mathrm{N}-\mathrm{G}$ is $0.8 \mathrm{wt} \%, 1.0 \mathrm{wt} \%$, and $1.2 \mathrm{wt} \%$. Futhermore, the titanium complex grease modified with nano-graphite with a concentration of 0.8 wt\% is the optimum grease. Subsequently, the influence of load on the tribological properties of grease containing the optimum concentration ( $\mathrm{N}-\mathrm{G}$ ) was studied. Compared to the base grease, the optimum grease showed a lower average friction coefficient, smaller diameter and better tribological performance under the same experimental load. The influence of dispersion homogeneity of N-G on the tribological properties of titanium complex grease was also investigated. The base titanium complex grease and titanium complex grease modified with nano-graphite were synthesized in the laboratory and their tribological properties were evaluated via the four-ball test. The worn surface of their wears scar was observed using SEM and the states of the typical elements were analyzed via XPS. It was uncovered that nano-graphite can improve the tribological properties of titanium complex grease due to the physical friction reduction by nano-graphite due to its interlayer slide and the supplemental effect of the tribochemical reaction anti-wear film composed of $\mathrm{TiO}_{2}$ and $\mathrm{Fe}_{3} \mathrm{C}$.
\end{abstract}

\section{Introduction}

Numerous studies have been conducted in the past few years on the tribological performance and application of additives in lubricating grease. However, they focus on lithium-based grease. $^{1,2}$ In addition, with the popularization of lithium batteries, the production costs of LiOH used to synthesize lithium-based grease have increased sharply. Besides, the dropping point of lithium grease is not high enough. Thus, it is necessary to develop new types of lubricating grease.

Titanium complex grease is a promising type of grease owing to its outstanding combined properties such as high dropping point, good wear resistance, excellent load carrying ability, low pollution and good compatibility with mating surfaces. ${ }^{3-5}$ Furthermore, compared to lithium base grease, titanium complex grease possesses a wider application temperature range and better anti-wear properties. Therefore, it is desirable to widen its application. Nevertheless, there is still room for improvement in the tribological properties of titanium complex grease, but studies on it are very limited. Shen et al. ${ }^{6}$ improved the tribological properties of titanium complex grease by modifying it with nano- $\mathrm{CeO}_{2}$ and isobutylene sulfide (SIB). The

School of Mechctronics Engineering, Harbin Institute of Technology, Harbin, 150001, P. R. China.E-mail:qujianjun@hit.edu.cn mechanism of friction reduction and anti-wear was uncovered to be due to the generation of a chemical film, which was formed by the reaction between the additives and worn surface. However, it is an environmental hazard to employ SIB. Lubricants modified with various additives ${ }^{7-11}$ were proven to have better tribological properties by researchers. Meanwhile, carbon nanoparticles have drawn attention in the lubrication field due to their excellent wear resistance, thermal stability, ${ }^{12}$ and environmental friendliness.

Owing to its unique two-dimensional structure with singlelayer carbon atom thick, graphene has self-lubricating and good adhesion properties. Dan Zheng ${ }^{13}$ discovered that the addition of graphene could improve the tribological properties of lubricants owing to the protective film formed by graphene. Bahaa M. Kamel ${ }^{14}$ reported that graphene could reduce the frictional coefficient and improve the load-carrying properties of calcium grease, and the mechanism uncovered was that the protective film was deposited on the worn surface.

Different from the thinner layer of graphene with a thickness of $0.8-1.2 \mathrm{~nm}$ and diameter of $0.5-5 \mu \mathrm{m}$, nano-graphite (N-G) presents a thickness of 5-40 nm and a larger diameter of 1-15 $\mu \mathrm{m}$. Graphene is a single layer stripped from sheets of nanographite. Nano-graphite can be considered as multiple layers of carbon atoms with a thickness on the nanoscale. $\mathrm{Yu} \mathrm{Su}^{15}$ discovered that (N-G) of various sizes and additive concentration 
could improve tribological behaviors of vegetable oil, and the mechanism uncovered was nano-graphite was physically deposited on the worn surface. Flavio A. C. Vidal ${ }^{16}$ studied the effect of $\mathrm{N}-\mathrm{G}$ from different processes on tribological performance of mineral oil, with the results indicating that the graphite nanoplatelets obtained through an exfoliation process had better friction reduction and wear resistance compared with ordinary $\mathrm{N}$ $\mathrm{G}$, and the mechanism was revealed as the sliding effect between the nano-graphite layers. H. D. Huang ${ }^{17}$ applied micron graphite and N-G to paraffinic-based oil to improve its tribological properties, and the results indicated N-G performed better than micron graphite due to the N-G film deposited on the worn surface. Zhang Zuchuan ${ }^{\mathbf{1 8}}$ found that nano-graphite improved the tribological properties of $\mathrm{PAO}_{4}$ oil.

The research above focused on the application of carbon nano-particles in oil. However, it is difficult to disperse carbon nano-particles uniformly and stably in lubricating oil, even though the surface is modified. In contrast, it is relatively easy to uniformly and stably disperse them in lubricating grease due to its special soap fibers. Therefore, the application of nanoparticles in grease has great potential. Titanium complex grease is a promising new type of grease, and the application of $\mathrm{N}-\mathrm{G}$ in it has not been researched. In the above studies, the friction reduction and wear resistance mechanism of nanographite is attributed to the physically deposited film and physical slippage between the layers. However, it is insufficient for the physical function to reveal the antifriction mechanism since the friction interface is a complex environment including factors such as lubricant, additive, worn surface, frictional heat, and pressure. Thus, the tribochemical reaction of carbon nanoparticles on worn surfaces needs to be investigated. In addition, compared to graphene, the preparation cost of N-G is lower, which is more practical as a lubricant additive. Furthermore, nano-graphite production technology is very mature.

In this study, we synthesized titanium complex grease based on a mixed oil composed of 150BS and 350SN and the tribological properties of nano-graphite as an additive in grease were evaluated. The tribological tests were carried out using a fourball tester, after which the worn scars were analyzed via SEM and XPS to reveal the lubricating mechanism of titanium complex grease containing nano-graphite.

\section{Experimental details}

\subsection{Synthesis of titanium complex base grease and titanium complex nano-graphite grease}

2.1.1 Materials. All reagents and additives were of analytical grade and used without further purification. With the volume ratio of 150BS and 350SN oil of $1: 4$, the mixed oil was used as the base oil with a kinematic viscosity of $102-112 \mathrm{~mm}^{2}$ $\mathrm{s}^{-1}\left(40^{\circ} \mathrm{C}\right)$, which was obtained from Daqing no. 1 Lubricating Oil Factory, China. Benzoic acid and stearic acid were purchased from Tianjin chemical reagents factory, China. Titanium isopropoxide was purchased from Nanjing Shuguang Chemical Group CO., LTD (NSG), China. Distilled water was also used. Nano-graphite was procured from Nanjing Xianfeng Nano Material Technology Limited Company, China.
2.1.2 Synthesis device. A 3 L reaction vessel with a mechanical stirrer (type: $\mathrm{XFOH}-3$ ), which was obtained from Sichuan Zhongxing Petrochemical Research Institute, China. A three-roll grinder (type: SG65) was used for grease grinding, which was obtained from Qinhuangdao Funing Chemical Light Machinery Factory, China.

The process for the synthesis of the titanium complex base grease and titanium complex N-G grease was similar; therefore, they were displayed in one flow diagram in Fig. 1. The boxes filled with light pink are the materials and reaction samples for the base grease, the boxes filled with light blue represent the reaction conditions and the boxes in dark red dash lines only indicate the nano-graphite grease. The synthetic details of the titanium complex base grease and titanium complex nanographite grease are presented below.

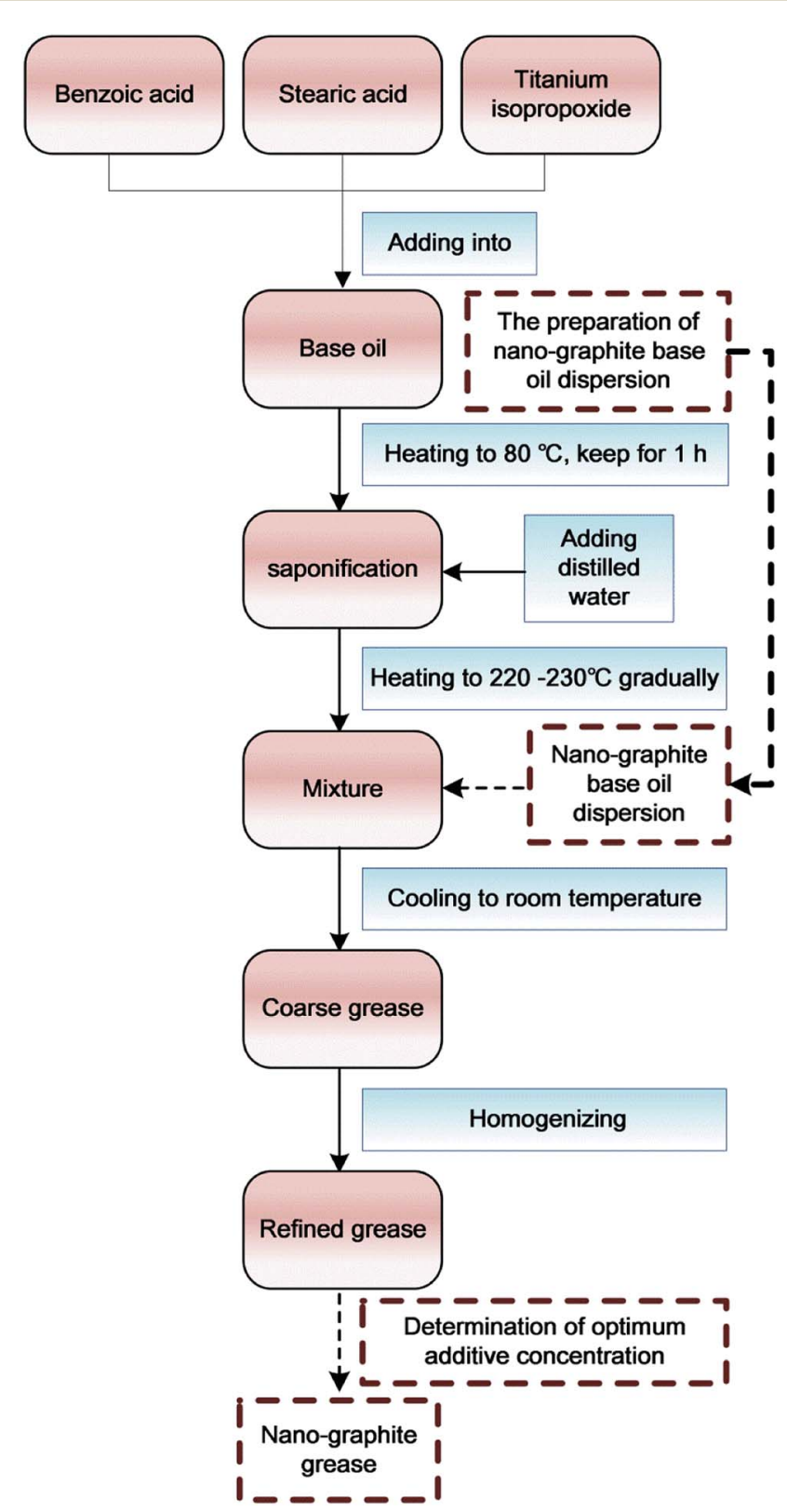

Fig. 1 Process flow diagram of the synthesis of the titanium complex base grease and titanium complex nano-graphite grease. 
As shown in Fig. 1, the synthetic details of the titanium complex base grease are as follows:

(1) A mixture of benzoic acid, stearic acid, titanium isopropoxide was added to the mixed oil ( $80 \mathrm{wt} \%)$ in $3 \mathrm{~L}$ reaction vessel. Then the mixture was mechanically stirred $(30 \mathrm{rpm}$ stirring speed, $20 \mathrm{~W}$ stirring power), and it was heated to $80{ }^{\circ} \mathrm{C}$ and this temperature was kept constant for $1 \mathrm{~h}$.

(2) Distilled water was added after saponification was completed, and the mixture was heated to $220-230{ }^{\circ} \mathrm{C}$ gradually.

(3) The mixture was cooled to ambient temperature after heating and stirring were stopped to obtain the coarse grease.

(4) Finally, to obtain the refined grease, the above grease was homogenized 5 times using a three-roll grinder.

The titanium complex grease was composed of $85 \mathrm{wt} \%$ base oil and $15 \mathrm{wt} \%$ thickener.

The synthetic details of the titanium complex nano-graphite grease are based on that of the base grease. As shown in Fig. 1, the extension for the synthesis of the N-G grease involved the preparation of a base oil-N-G dispersion (obtained by ultrasonically dispersing N-G in oil for $30 \mathrm{~min}$ ), adding this dispersion to the reaction mixture at $220-230{ }^{\circ} \mathrm{C}$, and the determination of the optimum additive concentration via a four-ball test. The titanium complex N-G grease was compounded by modifying the base grease with nano-graphite at the optimum additive concentration.
The titanium complex N-G grease was composed of 84$85 \mathrm{wt} \%$ base oil, $15 \mathrm{wt} \%$ thickener (benzoic acid/stearic acid titanium complex soap), and $0.2-1.4 \mathrm{wt} \%$ additive (nanographite).

Although titanium complex grease has been synthesized by other researchers, the reacting samples have never been shown. To better understand the synthesis of the titanium complex grease, samples from the reaction mixture at each chemical reaction stage were extracted and observed. Fig. 2 shows the reaction samples of each stage from the reaction temperature range of $50{ }^{\circ} \mathrm{C}$ to $230{ }^{\circ} \mathrm{C}$. Fatty acids did not dissolve in the base oil at $50{ }^{\circ} \mathrm{C}$ (sample 1). It is worth mentioning that at the temperature of $80{ }^{\circ} \mathrm{C}$, fatty acids dissolved in the base oil completely (sample 2) at the beginning, then the sample became dark in color after the addition of titanium isopropoxide (sample 3), and white floc appeared after the temperature was kept constant for $1 \mathrm{~h}$ and distilled water added (sample 4). With an increase in the reaction temperature to $110^{\circ}$, sample 5 became cloudy. With a further increase in the reaction temperature to $140-170{ }^{\circ} \mathrm{C}$, the reaction samples became darker in color and gradually turned into a clear molten state (sample 6 to sample 7), and soap molecules were completely formed at $170{ }^{\circ} \mathrm{C}$. As the reaction temperature increased to $200{ }^{\circ} \mathrm{C}$, the transparency was reduced in sample 8 due to the tendency to form titanium complex soap fibers, which were derived from the orientation of the soap molecules due to the inter-polar end

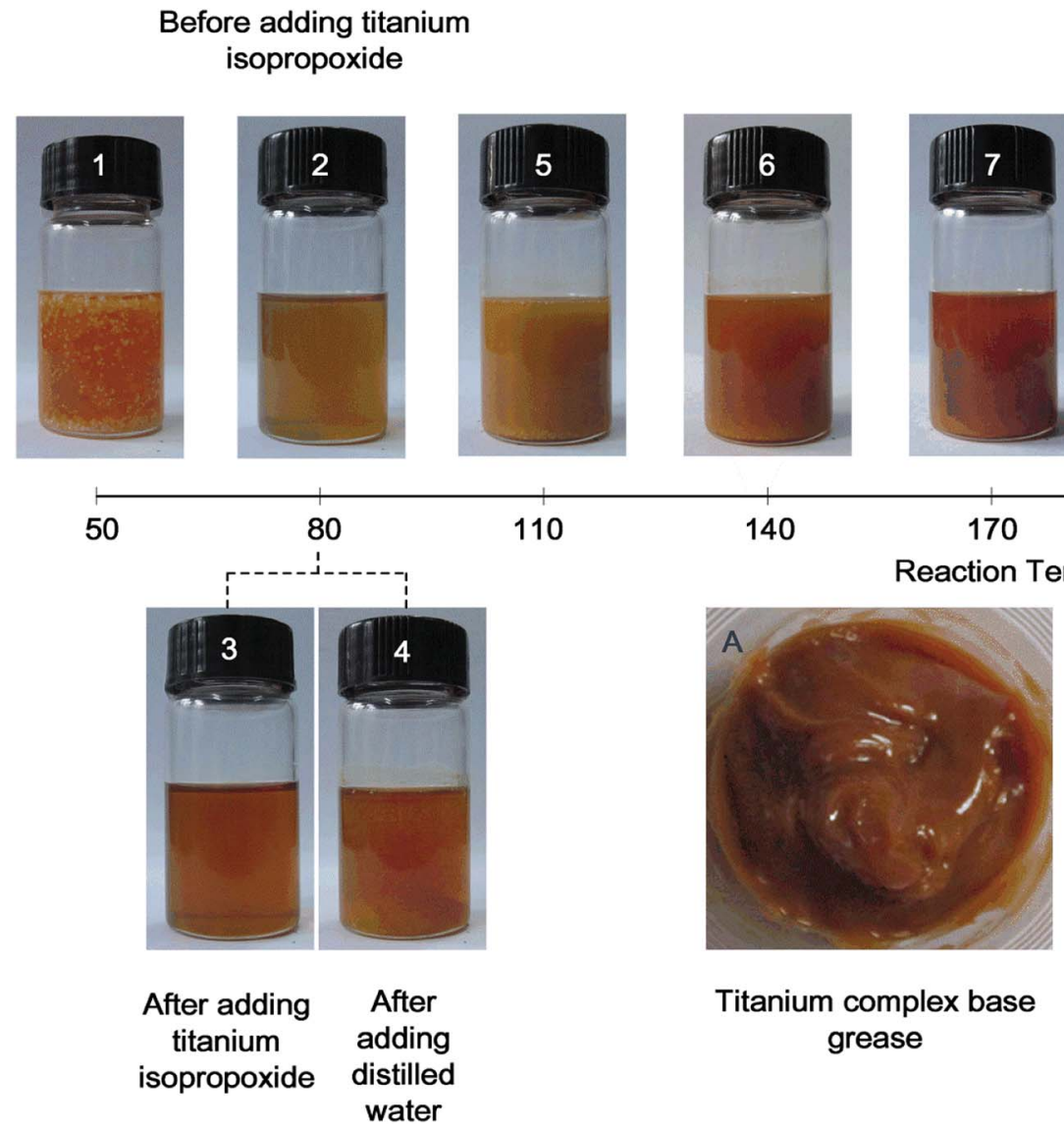

\section{After cooling}

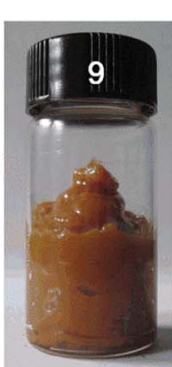

Titanium complex base grease

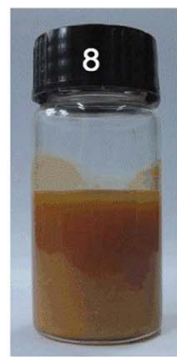

200

230

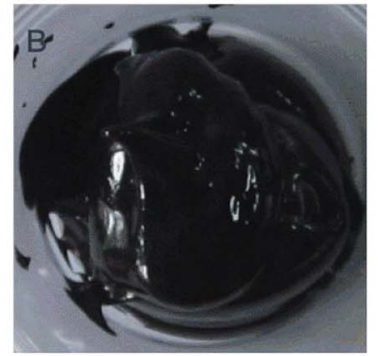

Titanium complex nano-graphite grease

Fig. 2 Samples at different chemical reaction stages in the synthesis of the complex titanium grease. 
attraction. As the reaction temperature increased to $230{ }^{\circ} \mathrm{C}$, titanium complex soap fibers were completely formed and titanium complex grease was formed after cooling to room temperature, locking the base oil in the soap fibers (Fig. 5).

In addition, samples $\mathrm{A}$ and $\mathrm{B}$ are titanium complex base grease and titanium complex N-G grease, respectively. The grease (sample A and B) was glossy and highly viscous. Titanium complex base grease (sample A) is light brown, while the titanium complex nano-graphite grease (sample B) is black due to the uniform addition of nano-graphite.

Fig. (3) shows the SEM morphology of N-G. It is representative of its state in the final grease product and the preparation details of the samples of N-G for SEM imaging are as follows.

(1) N-G was dispersed in ethanol at a weight concentration of $1 \%$.

(2) To disperse the agglomerated N-G, the N-G/ethanol solution was dispersed adequately for $1 \mathrm{~h}$ using an ultrasonic cleaner (type: SB2200).

(3) The dispersed N-G/ethanol solution was dropped onto the smooth surface of a silicon slice (size $10 \mathrm{~mm} \times 10 \mathrm{~mm}$ ) using a dropper.

(4) The silicon slice with the N-G/ethanol solution on its surface was placed in constant temperature and humidity testing machine controlled by a microcomputer (type: TEMP 300) to dry it (temperature: $60{ }^{\circ} \mathrm{C}$ and time: $1 \mathrm{~h}$ ).

(5) The silicon slice with N-G on it was taken out, and then sprayed with platinum via magnetron sputtering for $120 \mathrm{~s}$.

(6) The nano-graphite was observed via SEM.
Fig. 3 (a)-(c) present different average sized N-G magnified at 5000 times for N-G with an average sheet diameter of $2 \mu \mathrm{m}, \mathrm{N}-\mathrm{G}$ with an average sheet diameter of $3.5 \mu \mathrm{m}$, and N-G with an average sheet diameter of $6 \mu \mathrm{m}$, respectively. Besides, Fig. 3d shows the SEM morphology of N-G $(2 \mu \mathrm{m})$ magnified at 40000 times, and it can be seen that N-G has a typical layered stacking structure and each layer has a thickness between $20 \mathrm{~nm}$ and $40 \mathrm{~nm}$. Thus, slip can occur between these layers under shear force.

\subsection{The measurement of tribological properties}

The dropping point and penetration were measured according to GB/T 3498 (similar to ASTM D2265) and GB/T 269 (similar to ASTM D217), respectively.

To determine the optimum additive concentration for the three types of $\mathrm{N}-\mathrm{G}$ with different diameters, the effects of $\mathrm{N}-\mathrm{G}$ concentration $(0.2,0.4,0.6,0.8,1.0,1.2,1.4,1.6$, and $1.8 \mathrm{wt} \%)$ on the average frictional coefficient (AFC) and diameter of wear scars (WSD) of the titanium complex base grease were studied under the conditions of load $392 \mathrm{~N}$, rotating speed $1450 \mathrm{rpm}$ and time $60 \mathrm{~min}$. Each test was carried out at each load with fresh grease. Subsequently, the optimum grease was prepared by modifying the base grease with the optimum additive concentration of nano-graphite. The effects of applied load (98, 206, 304, 392, 510, and $598 \mathrm{~N}$ ) on the AFC and WSD of base grease and optimum grease were investigated based on the conditions of rotating speed $1450 \mathrm{rpm}$ and time $60 \mathrm{~min}$. Each test was carried out at each load with fresh grease.
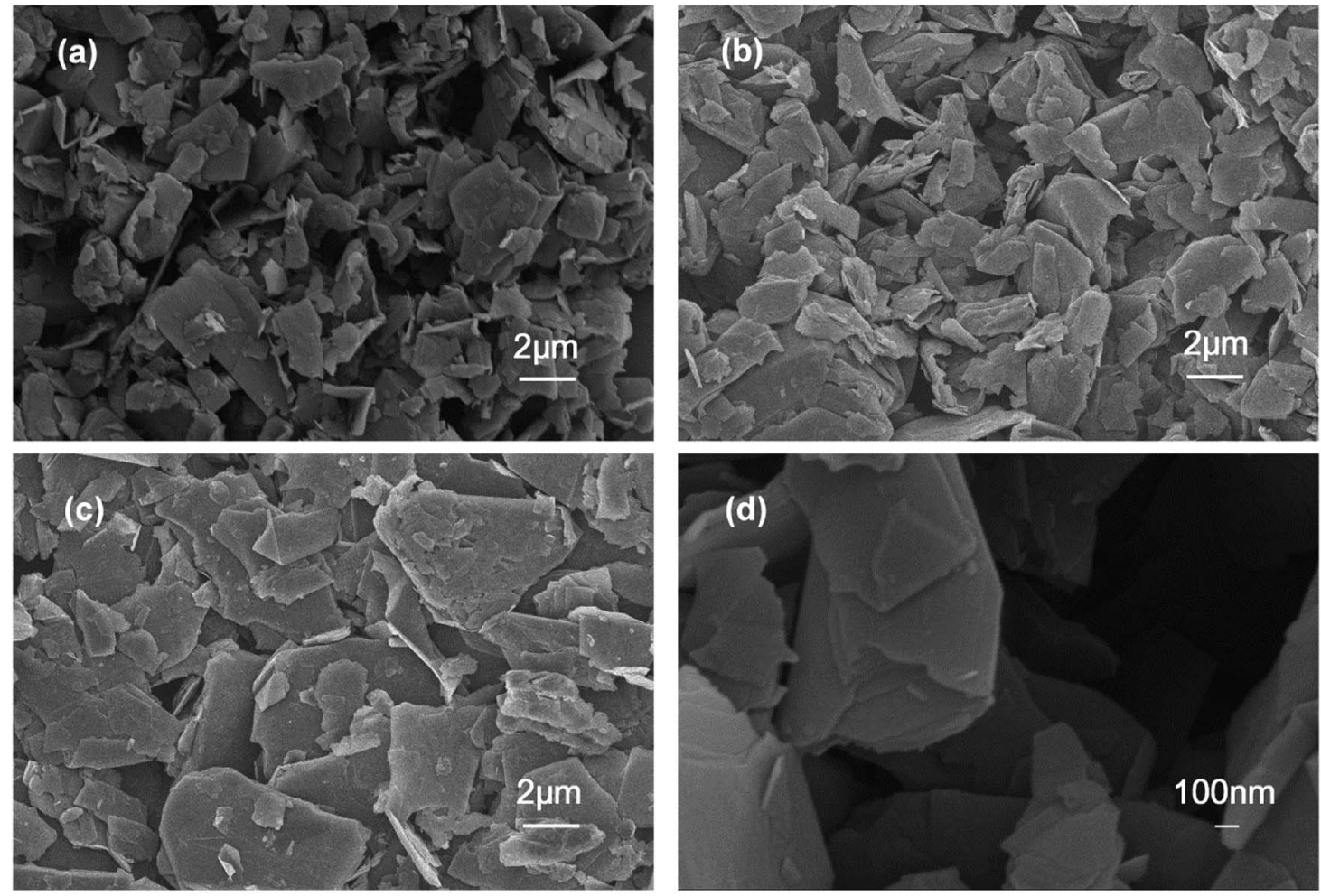

Fig. 3 SEM morphology of nano-graphite with different diameters: (a) nano-graphite with average sheet diameter of $2 \mu \mathrm{m}$, (b) nano-graphite with average sheet diameter of $3.5 \mu \mathrm{m}$, (c) nano-graphite with average sheet diameter of $3.5 \mu \mathrm{m}$ and (d) nano-graphite (2 $\mu \mathrm{m})$ magnified 40000 times. 
a

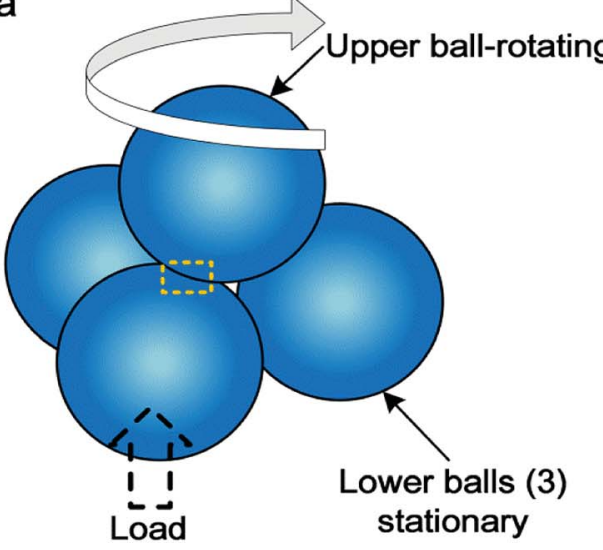

b

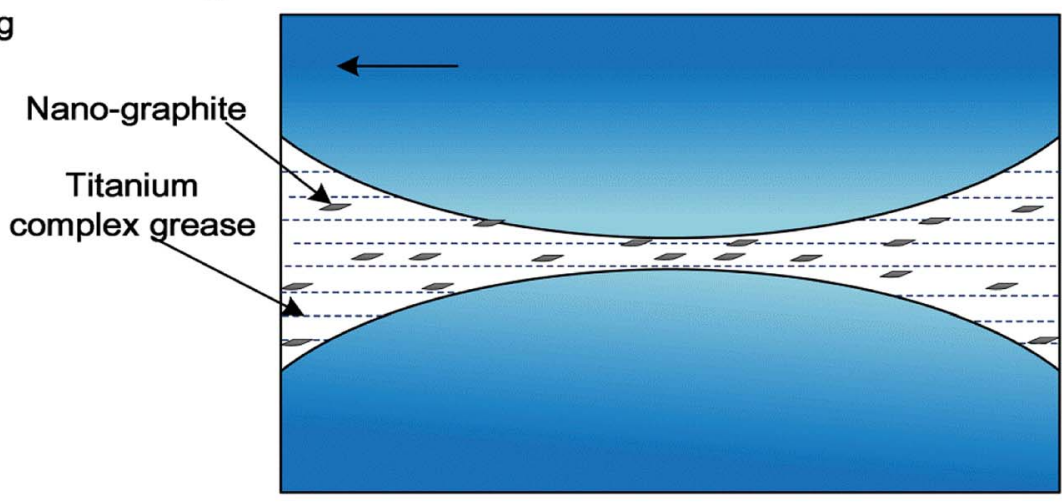

Fig. 4 Models of lubrication regimes in the four-ball tribosystem: (a) schematic of the four-ball tribosystem and (b) schematic of the lubrication area.

In addition, to investigate the effect of the dispersion homogeneity of N-G in the grease on tribological properties, two types of N-G/oil dispersions to modify the grease were prepared. The first was ultrasonically dispersed on oil for $30 \mathrm{~min}$, and the other for $60 \mathrm{~min}$.

The friction-reduction and anti-wear properties of the grease were characterized with the average frictional coefficient (AFC) and diameter of wear scars (WSD), respectively. The equipment used was a four-ball tester (type: MRS-10), and the steel balls were cleaned in acetone using an ultrasonic cleaner (type: SB2200) for $30 \mathrm{~min}$ and dried before testing. Fig. 4a shows a schematic of the four-ball tribosystem used in this study. In this system, the upper ball rotates, and the three lower balls remain stationary. The load is applied from the bottom of the lower balls, and the direction of the movement is indicated in the upper part of the models by an arrow. Fig. $4 \mathrm{~b}$ displays a schematic of the lubrication area. The nano-graphite and titanium complex grease filled in the lubricating area prevent the direct contact of the surfaces of the steel balls.

\subsection{The analysis of worn steel surface}

The worn surface of the wear scar was observed through SEM (type: Merlin Compact) and the states of the typical elements were analyzed via XPS (type: ESCALAB 250Xi).

\section{Results and discussion}

\subsection{Physical characteristics of titanium complex grease}

As shown in Fig. 5, the soap fiber of the titanium complex grease showed a structure of interconnected curly thin slices with consecutive cavities in them. In fact, this is the reason why the base oil is locked into the complex titanium soap fibers and also why the titanium complex grease has some unique properties, such as high dropping point and excellent anti-wear properties. The structure of interconnected curly thin slices enhanced of the soap fibers, which allows excellent load carrying ability and anti-wear properties.

Fig. 6 illustrates the variation in the penetration and dropping point with additive concentration of N-G with a diameter of $2 \mu \mathrm{m}$. As shown in Fig. 6a, the penetration decreased with an increase in
N-G concentration, which indicates that graphite had a thickening effect on the titanium complex grease. As shown in Fig. 6b, the dropping point of the base grease increased in the additive concentration range of $0-0.8 \mathrm{wt} \%$, but decreased in the range of 0.8-1.4 wt\% because the excess nano-graphite reduced the ability of the titanium soap fibers to lock the base oil. This indicates that $\mathrm{N}-\mathrm{G}$ has the effect of increasing the consistency and enhancing the heat resistance of the base grease.

\subsection{Tribological behavior of titanium complex grease}

3.2.1 Influence of additive concentration. Fig. 7 illustrates the variation in average frictional coefficient (AFC) and wear scar diameter (WSD) with additive concentration of three types of N-G with different sizes. For the AFC shown in Fig. 7a, compared to the base grease, it could be obviously found that the addition of three types of N-G with different sizes reduced the AFC. Also, the AFC did not increase until the additive concentrations reached certain values. For N-G with average sheet diameters of $2 \mu \mathrm{m}, 3.5 \mu \mathrm{m}$, and $6 \mu \mathrm{m}$, the optimum additive concentration was $0.8 \mathrm{wt} \%, 1.0 \mathrm{wt} \%$, and $1.2 \mathrm{wt} \%$, respectively. Under these concentrations, the AFC decreased by $14.6 \%, 13.9 \%$ and $12.9 \%$, respectively.

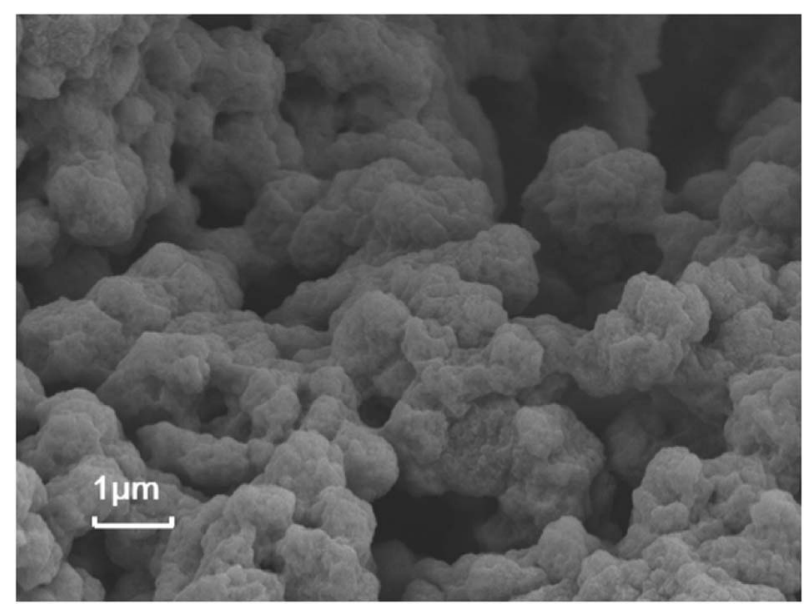

Fig. 5 Soap fiber of the titanium complex grease (20 000x). 

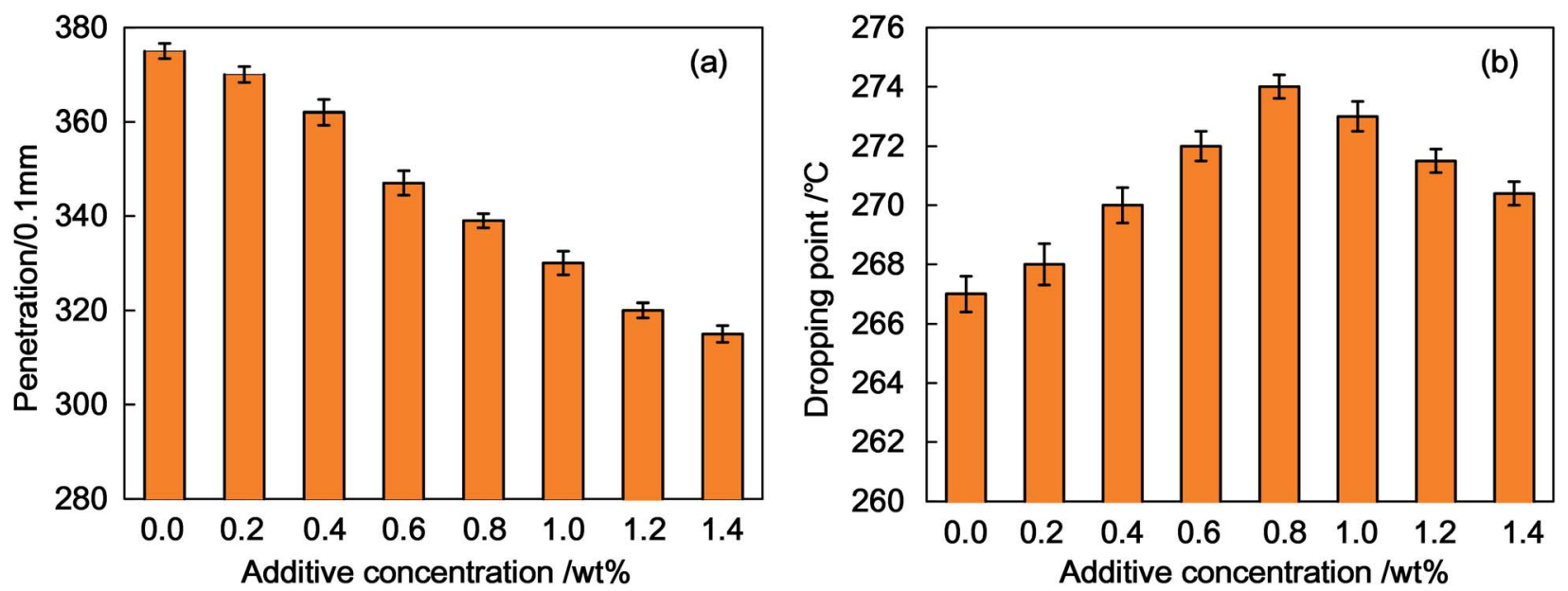

Fig. 6 Variations in the (a) penetration and (b) dropping point with additive concentration.

For the WSD shown in Fig. 7b, compared to the base grease, the addition of three types of N-G with different sizes reduced the WSD. Also, there were special additive concentrations for the three different sized N-G (size $2 \mu \mathrm{m}, 3.5 \mu \mathrm{m}$, and $6 \mu \mathrm{m}$ ) of $0.8 \mathrm{wt} \%, 1.0 \mathrm{wt} \%$, and $1.2 \mathrm{wt} \%$, respectively. The WSD did not increase until the optimum additive concentration was reached. Under these special additive concentrations, the WSD decreased by $2.29 \%, 2.20 \%$ and $2.12 \%$, respectively.

Thus, the results indicated that the optimum additive concentration increased with an increase in the average diameter of the N-G sheet, which was $0.8 \mathrm{wt} \%, 1.0 \mathrm{wt} \%$, and $1.2 \mathrm{wt} \%$ for $2 \mu \mathrm{m}, 3.5 \mu \mathrm{m}$, and $6 \mu \mathrm{m}$, respectively.

Therefore, titanium complex nano-graphite grease was the base grease modified with nano-graphite (size $2 \mu \mathrm{m}, 3.5 \mu \mathrm{m}$, and $6 \mu \mathrm{m}$ ) at the additive concentrations of $0.8 \mathrm{wt} \%, 1.0 \mathrm{wt} \%$, and $1.2 \mathrm{wt} \%$, respectively.

3.2.2 Influence of applied load. Fig. 8 discloses the relationship between the applied load and tribological properties of the base grease and optimum grease.
Fig. 8a shows a comparison of the AFC between the base grease and grease containing three different sized $(2 \mu \mathrm{m}, 3.5$ $\mu \mathrm{m}$, and $6 \mu \mathrm{m}) \mathrm{N}-\mathrm{G}$ at the optimum concentration.

As is shown in Fig. 8a, the AFC of the four grease samples increased similarly with an increase in load. Obviously, the AFC of the grease containing N-G was lower than that of the base grease at the same load, which indicates that the friction reducing properties of the titanium complex grease was improved by N-G due to the interlayer slide itself. It was also found that the AFC increased with an increase in the size of N-G under the same load, especially when the load was lower than $392 \mathrm{~N}$; however, the difference in AFC caused by the diversity in size of N-G was tiny when the load was higher than $392 \mathrm{~N}$. The AFC of the grease modified with N-G (size $2 \mu \mathrm{m}$ ) at $0.8 \mathrm{wt} \%$ was the lowest.

As shown in Fig. 8b, the WSD of the four grease samples increased similarly with an increase in load. Compared to the base grease, the WSD of the grease containing N-G was smaller at the same applied load, especially after $392 \mathrm{~N}$. The oil film of the base grease could stand the load over $392 \mathrm{~N}$, but the
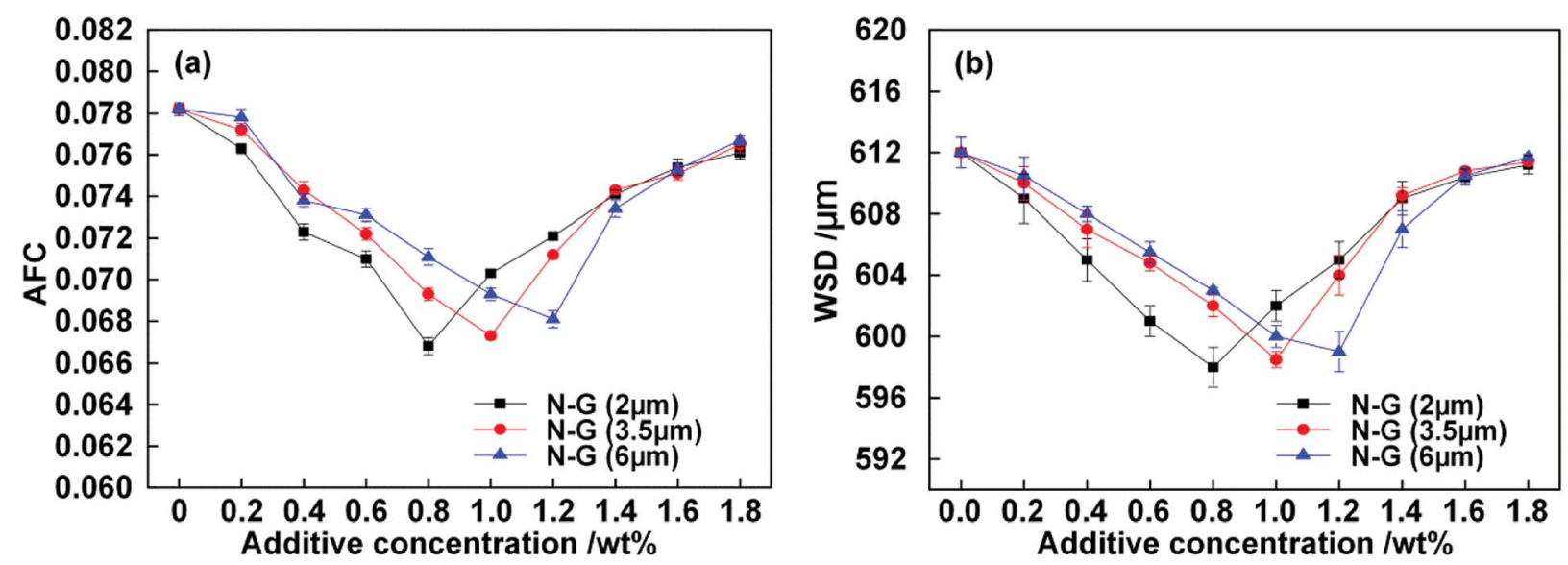

Fig. 7 Variations of in the AFC and WSD with additive concentration for the different sized nano-graphite: (a) AFC and (b) WSD (four-ball test, $1450 \mathrm{rpm}, 392 \mathrm{~N}$, and $60 \mathrm{~min}$ ). 

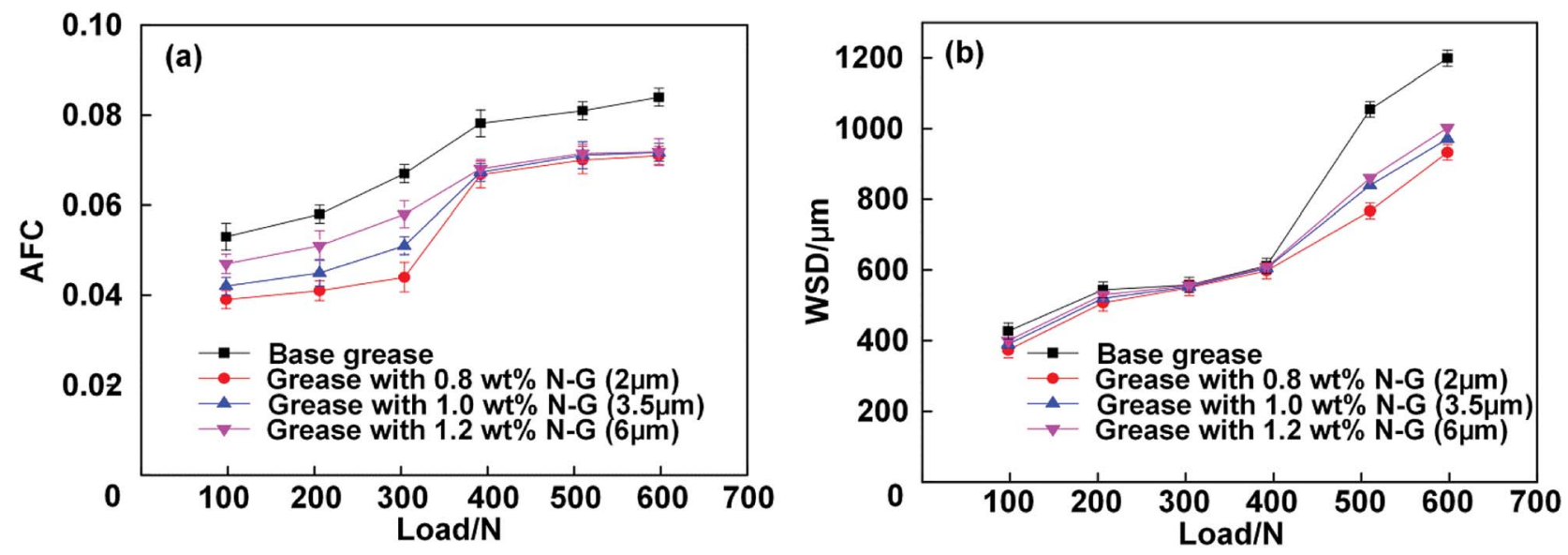

Fig. 8 Variations in the AFC and WSD from lubrication by grease modified with different sized nano-graphite with applied load: (a) AFC and (b) WSD (four-ball test, $1450 \mathrm{rpm}, 392 \mathrm{~N}$, and $60 \mathrm{~min}$ ).

strength of the film was enhanced markedly by N-G, which easily bore the higher load and led to an enlargement in difference between the WSD of the base grease and grease containing N-G when the load was more than $392 \mathrm{~N}$. It was also found that the WSD increased with an increase in the size of N$\mathrm{G}$ under the same load. The WSD of the grease modified with $\mathrm{N}$ $\mathrm{G}($ size $2 \mu \mathrm{m})$ at $0.8 \mathrm{wt} \%$ was the lowest.

The results demonstrated that the addition of N-G with the optimum additive concentration endowed the titanium complex grease with better friction reduction and anti-wear properties at any load.

Accordingly, as the ideal additive to the titanium complex grease, N-G should be the proper size and additive concentration. In this study, N-G with a thickness of $20-40 \mathrm{~nm}$ and average sheet diameter of $2 \mu \mathrm{m}$ was determined as the ideal additive, and its optimum additive concentration was $0.8 \mathrm{wt} \%$. The other additives such as PTFE, nano-titanium dioxide, and nano-silicon studied by $\mathrm{Chen}^{19}$ in titanium complex grease decreased the AFC by $29.07-34.58 \%, 22.97-35.98 \%$ and $24.47-$ 29.58 , and WSD by $4.95-5.46 \%, 4.58-8.95 \%, 1.8-4.55 \%$, respectively. Similarly, nano-graphite reduced the AFC and WSD by $14.1 \%$ and $2.28 \%$, respectively, as stated above, which are not so evident as that of PTFE, nano-titanium dioxide, and nanosilicon, but it has obvious advantages in anti-wear properties when the load is higher than $392 \mathrm{~N}$.

In addition, the lithium base grease modified with N-G applied by Cheng ${ }^{20}$ gave an $\mathrm{AFC}$ of 1.05 , which is higher than that of the titanium complex nano-graphite grease. Therefore, the friction reducing property of N-G in titanium complex grease is superior to that of lithium base grease.

In theory, nanoparticles with self-lubricating and anti-wear properties and are easy to disperse are good additives, but N$\mathrm{G}$ is an especially ideal additive for titanium complex grease in terms of tribological property improvement at high load.

From Fig. 7 and 8, it seems that a correlation exists between the AFC and WSD. From Fig. 7, it can be found that under the same applied load, the variations in AFC and WSD with additive concentration were almost the same. Both the AFC and WSD actually increased with an increase in additive concentration over the optimal point. From Fig. 8, it can be found that both the AFC and WSD increased with an increase in load; however, the former increased slower over $392 \mathrm{~N}$ and the latter increased faster over $392 \mathrm{~N}$. The relationship between AFC and WSD was similarly linear under an increasing load condition.

3.2.3 Influence of dispersion homogeneity. The dispersion homogeneity was improved by prolonging the ultrasonic dispersion time of N-G. Thus, to investigate the influence of dispersion homogeneity on the tribological properties of the titanium complex grease, $\mathrm{N}-\mathrm{G}$ with an average size $2 \mu \mathrm{m}$ was ultrasonically dispersed for different times. The SEM morphology of the sample dispersed for $30 \mathrm{~min}$ is shown in Fig. 3a in Section 2.1 and that for $60 \mathrm{~min}$ is shown as Fig. 9. It can be found that N-G after 60 min dispersion was more dispersed than that after $30 \mathrm{~min}$.

Fig. 10 shows the AFC and WSD as a function of applied load with lubrication by the different greases containing nanographite (dispersed for $30 \mathrm{~min}$ and $60 \mathrm{~min}$ ).

Fig. 10a shows a comparison of the AFC between the grease containing the N-G dispersed for $30 \mathrm{~min}$ and that for $60 \mathrm{~min}$. The variations in the AFC of the two greases with applied load

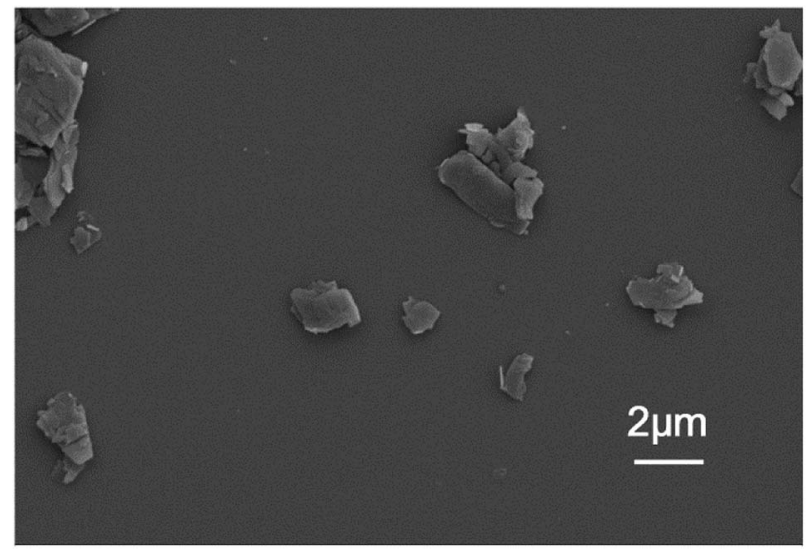

Fig. 9 SEM morphology of nano-graphite with an average sheet diameter of $2 \mu \mathrm{m}$ magnified at 5000 times after ultrasonic dispersion for $60 \mathrm{~min}$. 

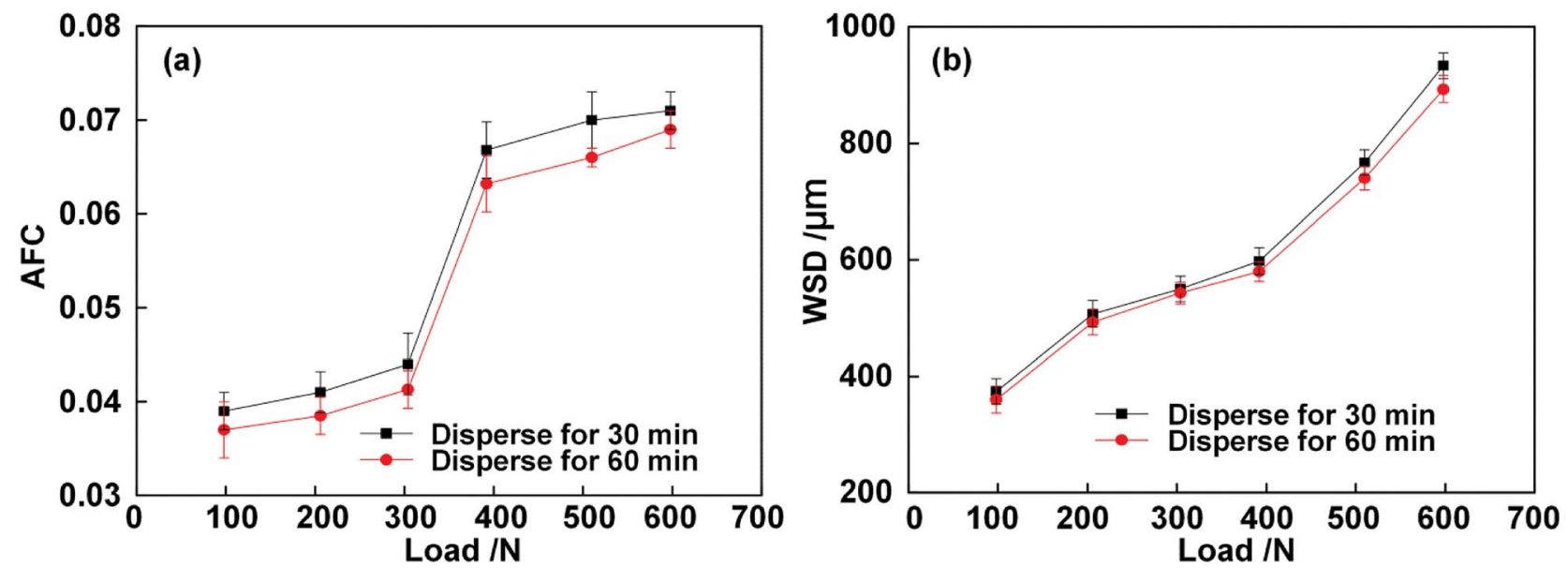

Fig. 10 Variations in the AFC and WSD with lubrication by grease containing nano-graphite dispersed for different times with applied load: (a) AFC and (b) WSD (four-ball test, $1450 \mathrm{rpm}, 392 \mathrm{~N}$, and $60 \mathrm{~min}$ ).
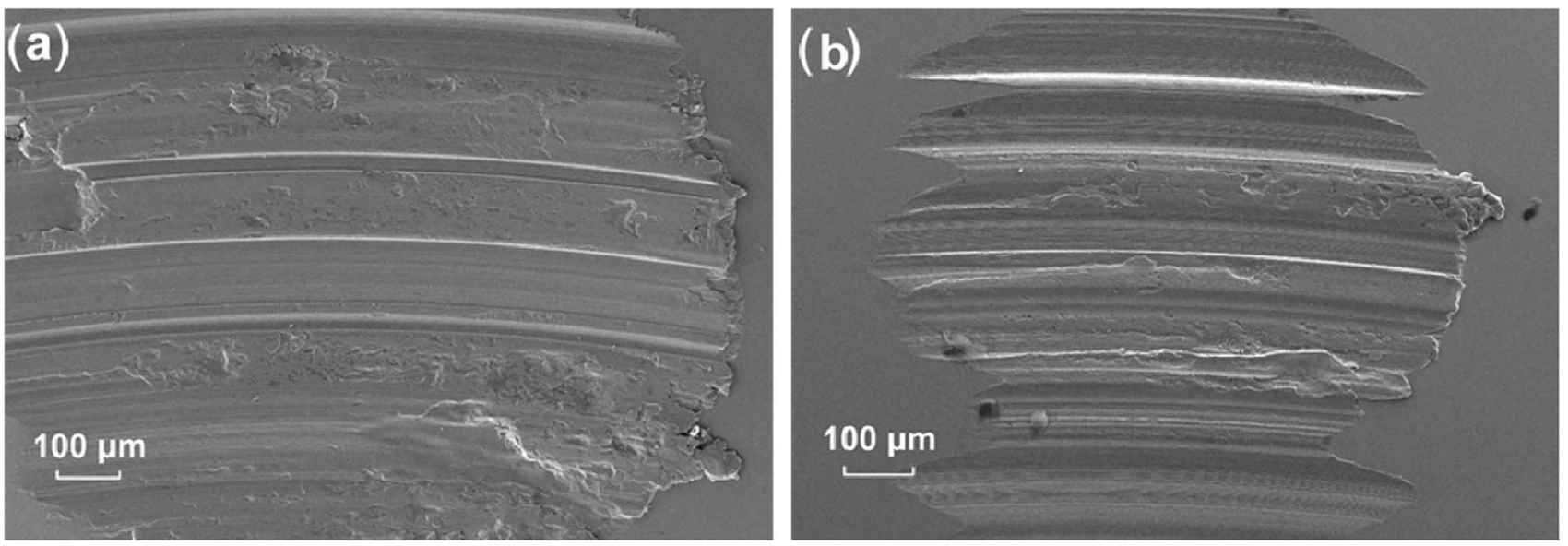

Fig. 11 SEM morphologies of the wear scar lubricated by different grease samples at $598 \mathrm{~N}$ for 60 min: (a) base grease (100 $\times$ ) and (b) optimum grease $(100 \times)$.

were exactly the same, and a longer dispersion time for N-G led to a slight reduction in AFC. As shown in Fig. 10b, the variations in the WSD of the two greases with applied loads were similar, and the WSD of the grease modified with N-G dispersed for 60 min was slightly lower than that of the grease modified with $\mathrm{N}-\mathrm{G}$ dispersed for $30 \mathrm{~min}$.

Thus, to a small degree, an increase in the dispersion homogeneity of nano-graphite improved the tribological properties of the grease.

\subsection{Lubricating mechanisms of titanium complex grease with nano-graphite}

To disclose the lubricating mechanisms of the titanium complex grease with N-G, the morphologies and the elemental state of the wear scars lubricated by the base grease and optimum grease were investigated via SEM and XPS.

Fig. 11 shows the morphologies of the wear scars lubricated by the base grease and grease containing nano-graphite with an average diameter of $2 \mu \mathrm{m}$ in its optimum additive concentration at $598 \mathrm{~N}$ for $60 \mathrm{~min}$. It can be obviously seen that the diameter of the wear scar lubricated by the base grease (Fig. 11a) is larger than that lubricated by the optimum grease (Fig. 11b), which accords with the above-mentioned wear scar diameters (Fig. 8b).

To investigate the state of the typical elements, Fig. 12 shows the high-resolution XPS spectra of C1s, Fe2P, O1s and Ti2P on the worn surfaces tested at $598 \mathrm{~N}$ for $60 \mathrm{~min}$. The corresponding relative atomic concentrations on the wear scar are shown in Table 1. The relative atomic concentration of $\mathrm{C}$ increased and that of the other elements decreased after introducing nanographite.

On the worn steel surface lubricated by the base grease and optimum grease, the peaks of element C (Fig. 12a) near $284.6 \mathrm{eV}, 284.9 \mathrm{eV}, 285.7 \mathrm{eV}$ and $288 \mathrm{eV}$ are attributed to C-H, C$\mathrm{C}, \mathrm{C}-\mathrm{O}-\mathrm{C}$, and $\mathrm{CO}_{3} / \mathrm{COOX},{ }^{21,22}$ respectively, which represent some organic groups in the titanium complex soap. This demonstrates that in the friction process, the composite titanium soap is adsorbed on the worn surface. As a result, a boundary film is formed by the carbonic organic matter from the compound titanium base grease. 

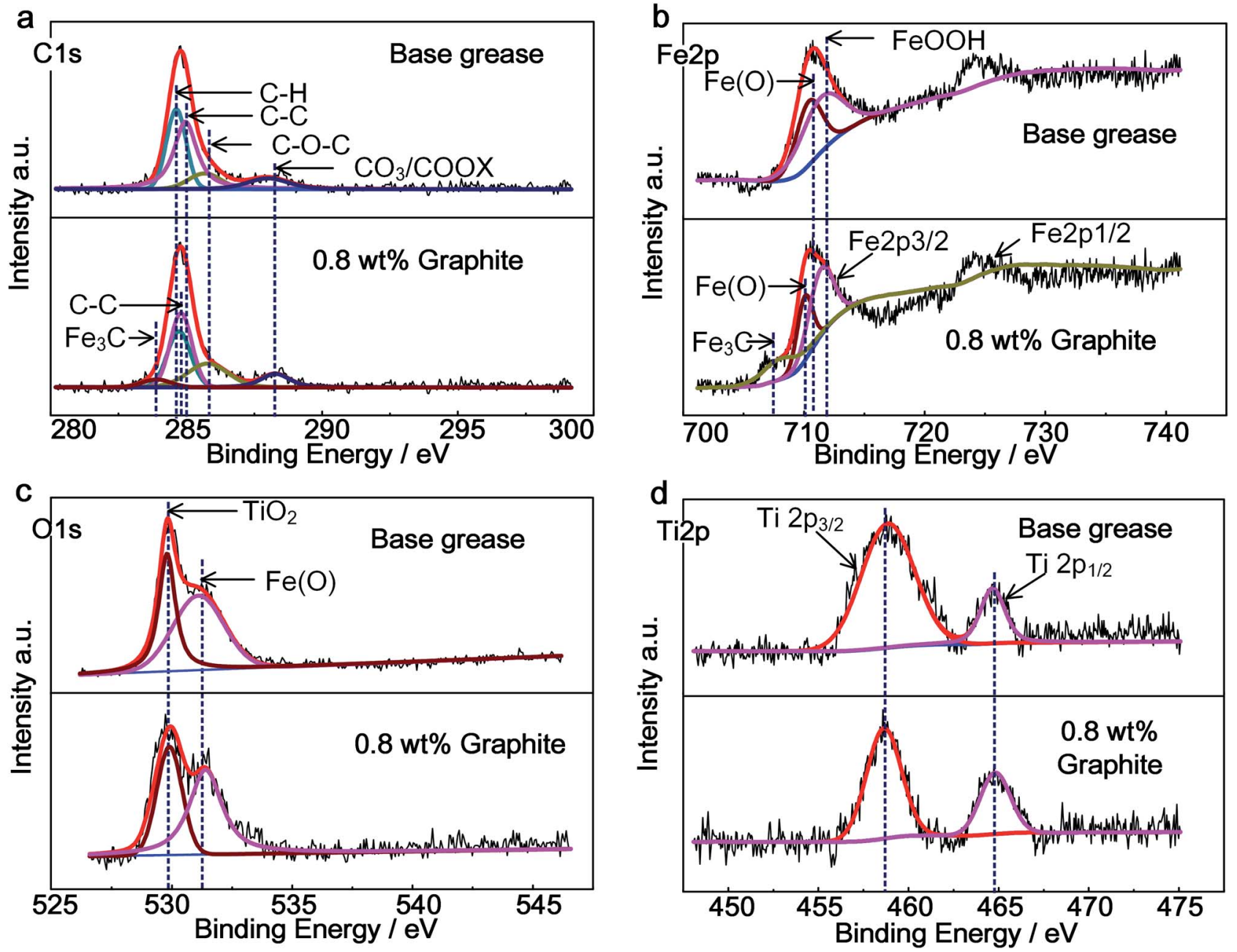

Fig. 12 XPS spectra of the typical elements on the wear scars of steel balls lubricated by the different grease samples at $598 \mathrm{~N}$ for $60 \mathrm{~min}$ : (a) C1s, (b) Fe2p, (c) O1s, and (d) Ti2p.

Table 1 Relative atomic concentration on wear scar

Relative atomic concentration/\%

\begin{tabular}{lcccc}
\cline { 2 - 5 } Additive & $\mathrm{C} 1 \mathrm{~s}$ & $\mathrm{Fe} 2 \mathrm{p}$ & $\mathrm{O} 1 \mathrm{~s}$ & Ti2p \\
\hline None & 78.01 & 14.15 & 2.37 & 0.71 \\
$0.8 \mathrm{wt} \%$ nano-graphite & 81.35 & 13.21 & 1.27 & 0.69
\end{tabular}

Besides the physical adsorbing film, the peaks of element $\mathrm{Fe}$ (Fig. 12b) near $710.4 \mathrm{eV}$ and $711.4 \mathrm{eV}$ and the peak of element $\mathrm{O}$ (Fig. 12c) near $531.4 \mathrm{eV}$ indicate that iron oxide was generated and deposited on the worn surface. The reason for this is that the surface of the steel was subjected to high pressure friction and the reaction between $\mathrm{O}$ and Fe elements from the worn steel generated $\mathrm{Fe}_{2} \mathrm{O}_{3}$, which was then deposited on the surface. Besides, the peak of element Fe (Fig. 12b) near $712.1 \mathrm{eV}$ indicates that $\mathrm{FeOOH}$ was generated.

In addition, the peak of element $\mathrm{O}$ (Fig. 12c) near $529.9 \mathrm{eV}$ and the peaks of element Ti (Fig. 12d) near $458.6 \mathrm{eV}$ (corresponding to $\mathrm{Ti}^{4+} 2 \mathrm{p}_{3 / 2}$ ) and $464.8 \mathrm{eV}$ (corresponding to $\mathrm{Ti}^{4+} 2 \mathrm{p}_{1 / 2}$ ) are attributed to titanium dioxide. This indicates that the titanium complex soap molecules decomposed and $\mathrm{TiO}_{2}$ was generated by tribochemical reaction. Then, a $\mathrm{TiO}_{2}$ film was deposited on the worn steel surface, which enhanced the wear resistance of the worn surface. ${ }^{23}$

Also, only for the worn steel surface lubricated by titanium complex grease containing $\mathrm{N}-\mathrm{G}$, its $\mathrm{C}$ element and Fe element had other peaks besides that from the base grease. The peaks of element C (Fig. 12a) near $283.9 \mathrm{eV}$ and element Fe (Fig. 12b) near $708.1 \mathrm{eV}$ are attributed to $\mathrm{Fe}_{3} \mathrm{C}$. This indicates that the N-G in the base grease was subjected to high pressure friction, where the carbon atoms infiltrated the worn steel matrix and formed a carburized layer, which is the main component of white cast iron. It had good wear resistance and improved the wear resistance of the titanium complex grease.

In addition, for the worn steel surface lubricated by titanium complex grease containing $\mathrm{N}-\mathrm{G}$, there was mutual anti-wear supplement between the $\mathrm{Fe}_{3} \mathrm{C}$ carburized layer and the $\mathrm{TiO}_{2}$ sedimentary layer. The $\mathrm{Fe}_{3} \mathrm{C}$ carburizing layer intermittently occupied the worn surface, and so did the formed $\mathrm{TiO}_{2}$ deposited layer. As a result, these two layers occupied the entire worn surface in a complementary way. 
From the above explanation, first, the complex titanium soap was adsorbed on the wear surface to form a physical adsorption lubricating film during the friction. Subsequently, two types of chemical reaction layers were generated, where the $\mathrm{Fe}_{2} \mathrm{O}_{3}$ layer indicates worn steel, and the nano-graphite reacted with the worn steel surface to form an $\mathrm{Fe}_{3} \mathrm{C}$ carburizing layer. The effect of the mutual anti-wear supplement between the $\mathrm{Fe}_{3} \mathrm{C}$ carburized layer and the $\mathrm{TiO}_{2}$ sedimentary layer improved the antiwear property of the base grease and the $\mathrm{TiO}_{2}$ deposited layer indicates the good anti-wear property of the titanium complex.

\section{Discussion}

The AFC of all the greases tested is in the range of 0.04-0.1, which indicates the friction and wear tests herein are dominated by boundary lubrication. The above results provide a better understanding of the generation of a friction film at the lubricating interface. The improvement in the friction reducing and anti-wear properties are attributed to the interaction of two factors: the physical boundary film that formed by the titanium complex soap molecules and N-G absorbed on the worn steel surface, and chemical reaction film generated by the reaction between the titanium complex soap molecules, N-G and worn steel substrate. Schematic diagrams of the lubricating mechanism for the lubricating grease are shown in Fig. 13. For a better understanding, this section deals with the mechanism of the two factors separately, although there is no clear division between the boundary and chemical film.

\subsection{Slip effect for nano-graphite}

As is shown in Fig. 13b, nano-graphite was involved in the frictional interface with the titanium complex grease. N-G has a typical layered stacking structure, and each layer has a thickness between $20 \mathrm{~nm}$ and $40 \mathrm{~nm}$ (Fig. 3). N-G was shorn at the steel ball moving direction, which led to slip between the layers.

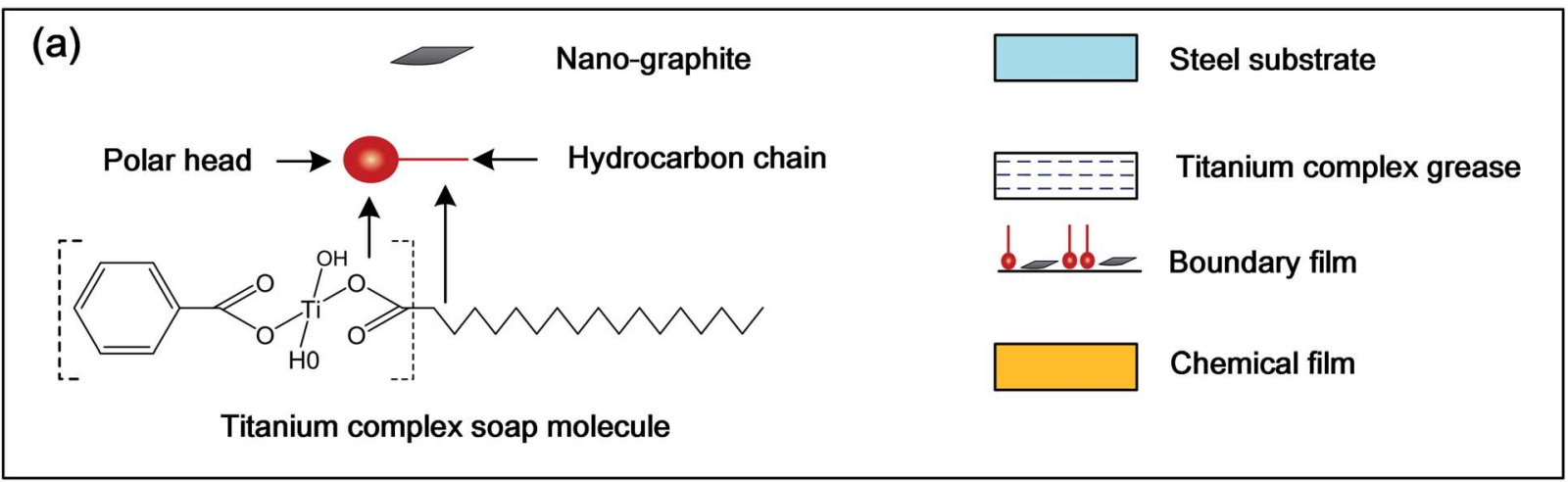

(b)

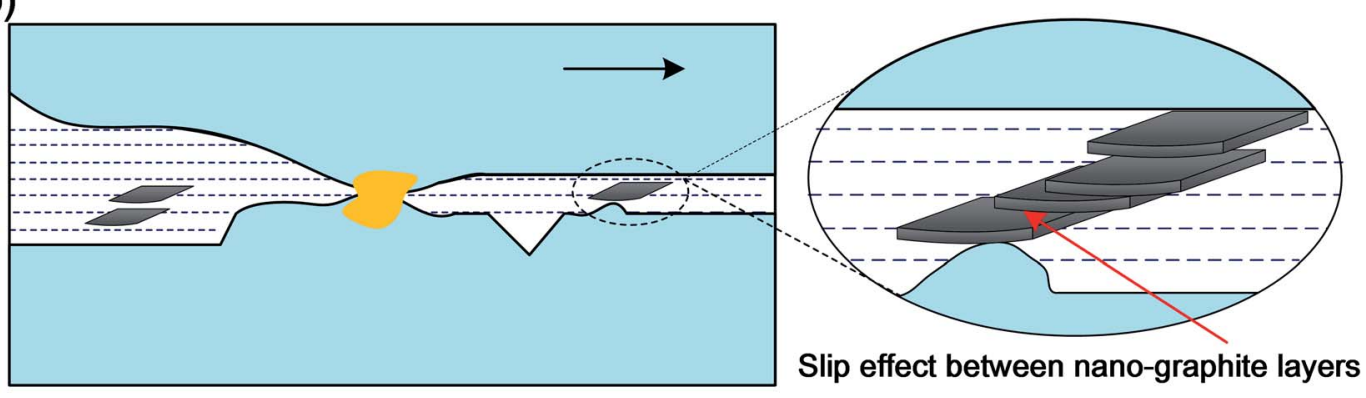

(c)

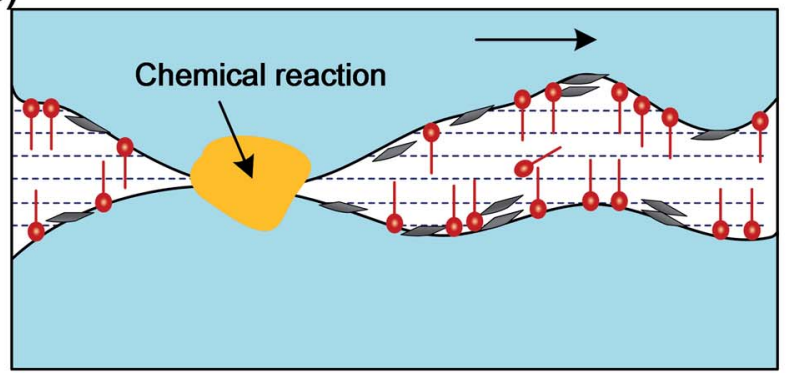

(d)

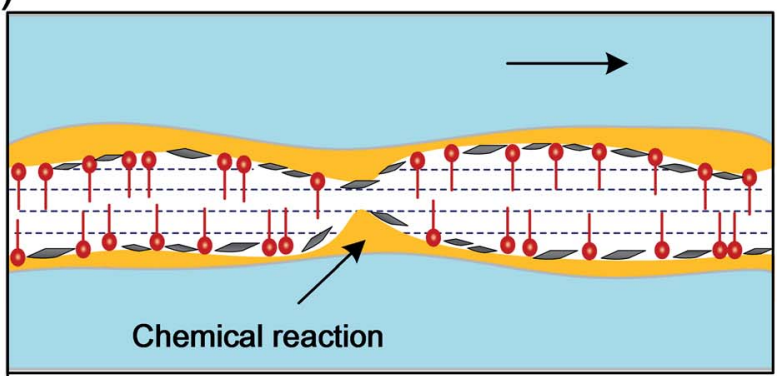

Fig. 13 Schematic diagrams of the lubricating mechanism for the lubricating grease: (a) structure of grease soap and notes, (b) slip effect for nano-graphite, (c) boundary film consisting of soap molecules and nano-graphite, and (d) boundary film and chemical reaction film. 
This is an advantage for improvement in the friction reducing properties of titanium complex grease.

\subsection{Boundary film}

Titanium complex soap molecules were absorbed on the worn surfaces with their polar groups anchored on the mental surface and hydrocarbon chain oriented away from the mental surface, which formed a boundary film (Fig. 13c and d) ${ }^{24}$ that could protect the worn steel surface. N-G was absorbed on the worn surfaces, which improved the strength of the boundary film (Fig. 13c and d). The friction reducing and anti-wear properties improved with an increase in the additive concentration of N-G due to the improvement in the strength of boundary film by the nano-graphite; however, with a further increase in additive concentration of $\mathrm{N}-\mathrm{G}$, the improvement in friction reducing and anti-wear properties of the titanium complex grease became weak (Fig. 7), which is due to the destruction of the boundary film by the high concentration of $\mathrm{N}-\mathrm{G}$. The $\mathrm{C}-\mathrm{H}$ and $\mathrm{C}-\mathrm{C}$ in Fig. 11a allowed the formation of the boundary film.

\subsection{Chemical reaction film}

A chemical reaction between titanium complex grease, N-G and steel substrate occurred under the condition of local high pressure (caused by the load), the collision of asperities on the worn steel surface and local high temperature (caused by friction). The local high pressure of the oil and collision of the surface asperities led to elastic and plastic deformation. Thereby, as noted, the increase in temperature and plastic deformation may give rise to the diffusion of the active atoms from the lubricating compounds onto the worn surface layer. As a result, complex inorganic chemical compounds (Fig. 13d) of iron (Fig. 12b) with carbon, titanium (Fig. 12d) and oxygen (Fig. 12c) originating from the lubricating additive and thickener were formed on the worn surface. The local high temperature and friction led to the decomposition of the titanium complex soap molecules, and Fig. $12 \mathrm{~d}$ indicated that $\mathrm{TiO}_{2}$ was generated and deposited on the worn surface, which improved the anti-wear properties of the titanium complex grease. FeC was in situ generated on the worn surface by the reaction between the carbon atoms from N-G and iron atoms from the worn surfaces. As a result, the mutual antiwear supplement between the $\mathrm{Fe}_{3} \mathrm{C}$ carburized layer and the $\mathrm{TiO}_{2}$ sedimentary layer improved the anti-wear properties of the titanium complex grease.

Thus, N-G can improve the friction reducing properties of titanium complex grease due to slip effect between N-G layers. The improvement in the anti-wear properties of the titanium complex grease was due to the enhancement of the strength of the boundary film by N-G on one hand, and the chemical antiwear chemical reaction film formed under local high pressure and high temperature on the other hand.

\section{Conclusions}

Titanium complex grease was synthesized using benzoic acid, stearic acid and tetraisopropyl titanate. N-G was chosen as an additive, and its effect on the friction reducing and anti-wear properties of titanium complex grease was studied. From our studies, the following conclusions can be drawn:

(1) Titanium complex grease was synthesized with the proven properties of good friction reduction, good wear resistance and high dropping point. Besides, the addition of N-G increased the dropping point of the base grease and decrease the penetration, and the effect of nano-graphite on its physical properties was weak.

(2) The optimum additive concentration of N-G with diverse diameters was proven to be different. As the most ideal N-G with an average diameter of $2 \mu \mathrm{m}$ in the titanium complex grease, its optimum additive was determined to be $0.8 \mathrm{wt} \%$. Compared with the base grease, the titanium complex nano-graphite grease had better friction reducing and antiwear properties.

(3) Under the condition of boundary lubrication, a $\mathrm{TiO}_{2}$ deposit layer was formed by the tribochemical reaction of titanium soap, besides the boundary film physically adsorbed on the worn surface. However, an in situ $\mathrm{Fe}_{3} \mathrm{C}$ carburizing layer was formed through tribochemical reaction between N-G and worn steel surface and the supplemental effect between the $\mathrm{TiO}_{2}$ deposit layer and $\mathrm{Fe}_{3} \mathrm{C}$ carburizing layer, which enhanced the antiwear properties of titanium complex grease.

\section{Conflicts of interest}

There are no conflicts to declare.

\section{Acknowledgements}

The authors thank the financial support by the National Key Basic Research Program of China (973 Program) (No. 2013CB632305).

\section{Notes and references}

1 G. Zhao, Q. Zhao, W. Li, X. Wang and W. Liu, Lubr. Sci., 2014, 26, 43-53.

2 J. Yan, H. Zeng, T. Liu, J. Mai and H. Ji, Tribol. Trans., 2016, 1-8, DOI: 10.1080/10402004.2016.1194506.

3 A. Kumar, S. C. Nagar and K. R. Naithani, NLGISpokesman, 1998, 62, 20-27.

4 A. Kumar, B. D. Mittal and C. Kannan, NLGI Spokesman, 1996, 60, 10-18.

5 A. Kumar, E. Sayanna, A. S. Verma, et al., NLGI Spokesman, 1994, 58, 25-29.

6 T. Shen, D. Wang, J. Yun, Q. Liu, X. Liu and Z. Peng, Tribol. Int., 2016, 93, 332-346.

7 H. Zhou, J. Dispersion Sci. Technol., 2009, 30, 488-494.

8 H. Yang, M. Yang and R. Guo, J. Dispersion Sci. Technol., 2005, 26, 477-482.

9 F. Chiñas-Castillo, J. Lara-Romero and J. F. Jiménez-Jarquin, J. Dispersion Sci. Technol., 2014, 35, 1665-1674.

10 J. Wang, X. Guo, Y. He, M. Jiang and R. Sun, RSC Adv., 2017, 7, 40249-40254.

11 X. Wu, Q. Zhao, M. Zhang, W. Li, G. Zhao and X. Wang, RSC Adv., 2014, 4, 54760-54768. 
12 H. D. Huang, J. P. Tu, L. P. Gan, T. Z. Zou, C. Z. Li and X. B. Zhao, Tribology, 2005, 25, 312-316.

13 D. Zheng, Z.-b. Cai, M.-x. Shen, Z.-y. Li and M.-h. Zhu, Appl. Surf. Sci., 2016, 387, 66-75.

14 B. M. Kamel, A. Mohamed, M. El Sherbiny, K. A. Abed and M. Abd-Rabou, J. Dispersion Sci. Technol., 2016, 38, 14951500.

15 Y. Su, L. Gong and D. Chen, J. Nanomater., 2015, 2015, 1-7. 16 F. A. C. Vidal and A. F. Ávila, J. Tribol., 2014, 136, 031603.

17 H. D. Huang, J. P. Tu, L. P. Gan and C. Z. Li, Wear, 2006, 261, 140-144.
18 Z. Zhang, Z. Cai, J. Peng and M. Zhu, J. Phys. D: Appl. Phys., 2016, 49, 045304.

19 J. Chen, Tribol. Lett., 2010, 38, 217-224.

20 Z.-L. Cheng and X.-X. Qin, Chin. Chem. Lett., 2014, 25, 13051307.

21 X. Ji, Y. Chen, G. Zhao, X. Wang and W. Liu, Tribol. Lett., 2010, 41, 113-119.

22 J. Chen, Tribol. Lett., 2010, 40, 149-154.

23 M. L. Vera, M. R. Rosenberger, C. E. Schvezov and A. E. Ares, Nanomater. Nanotechnol., 2015, 5, 6.

24 A. Adhvaryu, C. Sung and S. Z. Erhan, Ind. Crops Prod., 2005, 21, 285-291. 